\title{
Phagocytic potential of pulmonary alveolar epithelium with particular reference to surfactant metabolism
}

\author{
B. C O R R I N \\ Department of Morbid Anatomy, St. Thomas's Hospital Medical School, London, S.E.I
}

Finely divided thorium and carbon were injected into the rat lung via the trachea and their uptake was studied electron microscopically. Small amounts of thorium were found in the lamellar vacuoles of the granular pneumocytes. Their presence was maximal at 24 hours and they later disappeared from these cells. This phenomenon is thought to represent a passive inflow as the vacuoles open on to the alveolar surface to discharge their content of surfactant, rather than evidence that the granular pneumocyte is concerned in surfactant disposal. An explanation reconciling the secretory nature of the vacuoles with their previously demonstrated content of lysosomal enzymes is advanced. Small quantities of thorium dioxide were ingested by the squamous pneumocytes and a little transferred to interstitial macrophages, but this is a minor route of disposal, the bulk of the material being ingested by alveolar macrophages. The limited phagocytic potential of the alveolar epithelium contrasts with that of the alveolar macrophages and is not taken to support the concept of an epithelial derivation of alveolar macrophages.

Whilst pulmonary macrophages are avidly phagocytic, the alveolar epithelial cells are generally held not to show such properties. The squamous epithelial cells (type I pneumocytes) form part of the thin air/b!ood barrier whilst the granular (type II) pneumocytes are thought to produce a surface-active phospholipid essential for the stability of the lung. The type II pneumocytes possess large osmiophilic inclusions, the presence of which correlates well with that of surfactant (Buckingham and Avery, 1962; Klaus, Reiss, Tooley, Piel, and Clements, 1962), and the inclusions are therefore widely accepted as representing surfactant secretion vacuoles. Recently, however, Niden (1967) has pointed out that the vacuoles could equally well represent ingested surfactant which had been synthesized elsewhere. Illustrations of the vacuoles communicating with the alveolar space (Bensch, Schaefer, and Avery, 1964 ; Corrin, Clark, and Spencer, 1969) purport to show extrinsic secretory activity, but the direction taken by a dynamic process cannot be determined in fixed tissue, and such appearances could equally well represent phagocytic activity (Niden, 1967). In common with other workers, we have demonstrated lysosomal enzymes within these vacuoles (Corrin and Clark, 1968 ; Corrin et al., 1969) which have therefore been regarded as lysosomal derivatives specially adapted for the secretion of surfactant (Sorokin, 1966), but the phago- somal nature of the vacuoles propounded Niden provides a simpler explanation for the presence of lysosomal enzymes. Niden also describes ingestion of foreign material by type II $\overrightarrow{\overrightarrow{\hat{O}}}$ pneumocytes, and brief supportive reports are pro- $\exists$ vided by Ladman and Finley (1966) and Suzuki, Churg, and Smith (1968). As this is contrary to the generally held view founded on the earlier work of Karrer $(1958,1960)$, it was decided to reinvestigate the phagocytic properties of alveolar $x$ epithelium, using finely divided thorium and $\frac{3}{3}$ carbon.

\section{MATERIALS AND METHODS}

Adult male rats of an albino strain free of respira- $\frac{D}{0}$ tory disease were used. Under light ether anaesthesia they were injected by the intratracheal route (King, O Harrison, Mohanty, and Yoganathan, 1958) with $0.5 \mathrm{~N}$ $\mathrm{ml}$. of undiluted Thorotrast (Testagar, Detroit), a N $25 \%$ stabilized colloidal solution of thorium dioxide, $\omega$ or with $0.4 \mathrm{ml}$. of a carbon suspension (Pelikan $\mathrm{C} 11$ / 1431a, Günther Wagner, Hannover) diluted 1 in 200 with $0.9 \mathrm{~N}$ saline. The animals were maintained on $\bar{\Phi}$ water and a stock diet until killed with ether or? carbon monoxide (coal gas) at 3, 19, 22, 24, 26, 48. 0 and 120 hours after injection of thorium, and 3 andō 48 hours after injection of carbon. The fixative used疋 was cold $\left(4^{\circ} \mathrm{C}\right.$.) methanol-free $4 \%$ formaldehyde in $\frac{\text { Pे }}{0}$

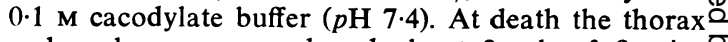
and neck were opened and about $2 \mathrm{ml}$. of fixative 


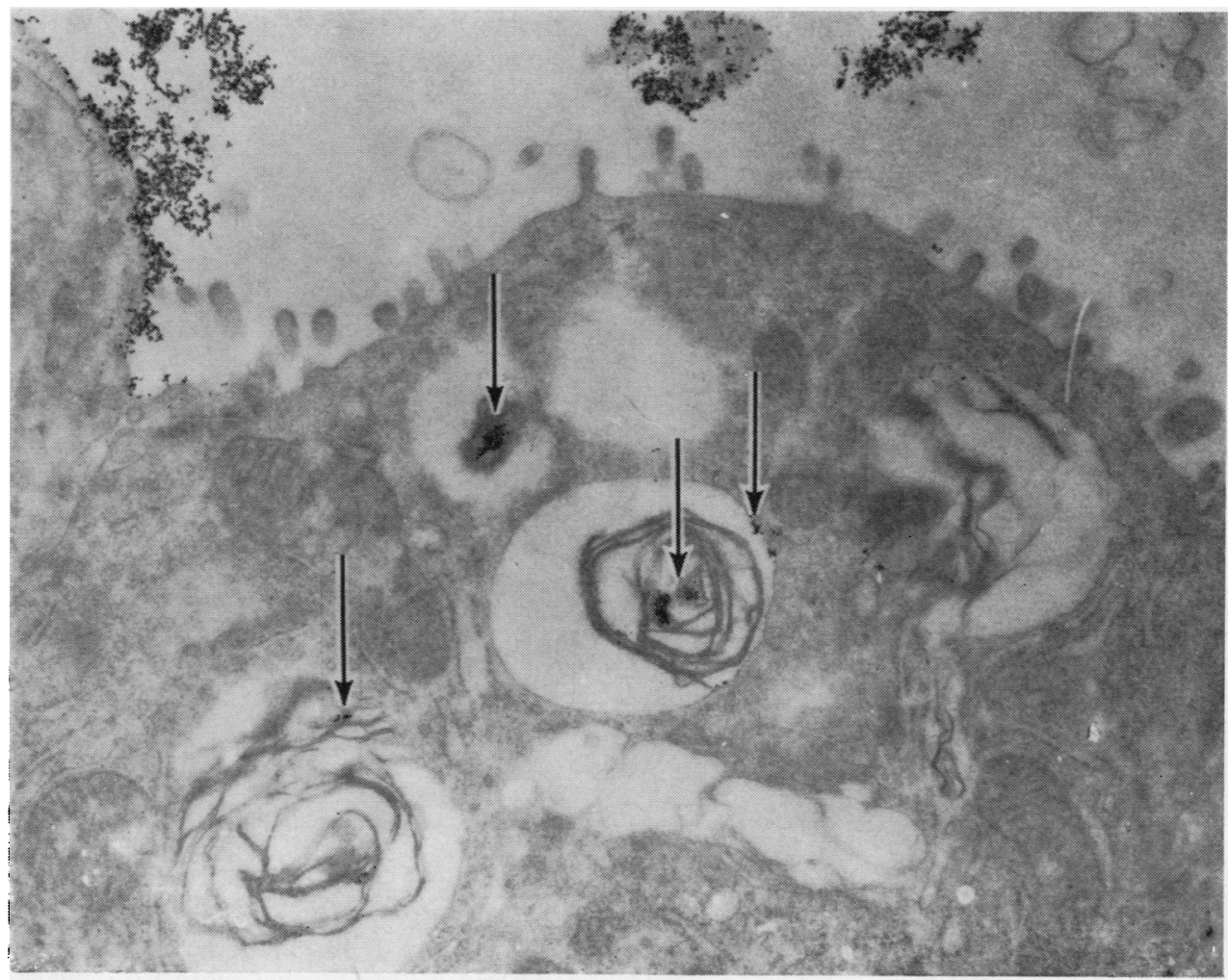

FIG. 1. A type II pneumocyte containing small amounts of thorium (arrows) within its lamellar vacuoles, 22 hours after injection. Large amounts of thorium are free in the alveolar space. Unstained $\times 19,000$.

was gently instilled into the lungs via the trachea. The trachea was then tied off and, together with the lungs, was placed in an excess of fixative for about 30 minutes. Small pieces of lung tissue were then fixed overnight in formaldehyde and for a further 30-60 minutes in osmium tetroxide before processing to Epon. Thin sections were examined electron microscopically, first unstained and again after contrast enhancement with lead citrate or lead citrate and uranyl acetate.

\section{RESULTS}

The injection technique itself caused a few changes in the lung. Pinocytosis was prominent in type I pneumocytes, and in type II cells dilatation of endoplasmic reticulum channels was sometimes observed. Generally, however, the lung structure was well preserved.

Marked phagocytosis of thorium and carbon was evident in every alveolar macrophage at all stages of the experiment. The particles were incorporated into membrane-lined vacuoles and admitted to residual bodies of myelin figure type as little as 3 hours after injection, thus demonstrating the heterogeneity of secondary lysosomes. The process of phagocytosis by alveolar macrophages was described by Karrer (1960), and in this experiment attention was directed more towards the alveolar epithelium. In the earliest stages all epithelial cells were devoid of thorium, but in animals examined 19 to 26 hours after injection, thorium particles were found within type II pneumocytes. The amount of thorium in these cells was minute, but up to $52 \%$ of type II cells contained thorium at this time interval. Considering the scanty amounts of thorium present in these cells and the small volume of each cell examined in a 200 to $400 \AA$ thick section, the true proportion of type II cells containing thorium must be very much higher. Within the type II pneumocytes the thorium particles were confined to the lamellar inclusions, appearing at their periphery or between 


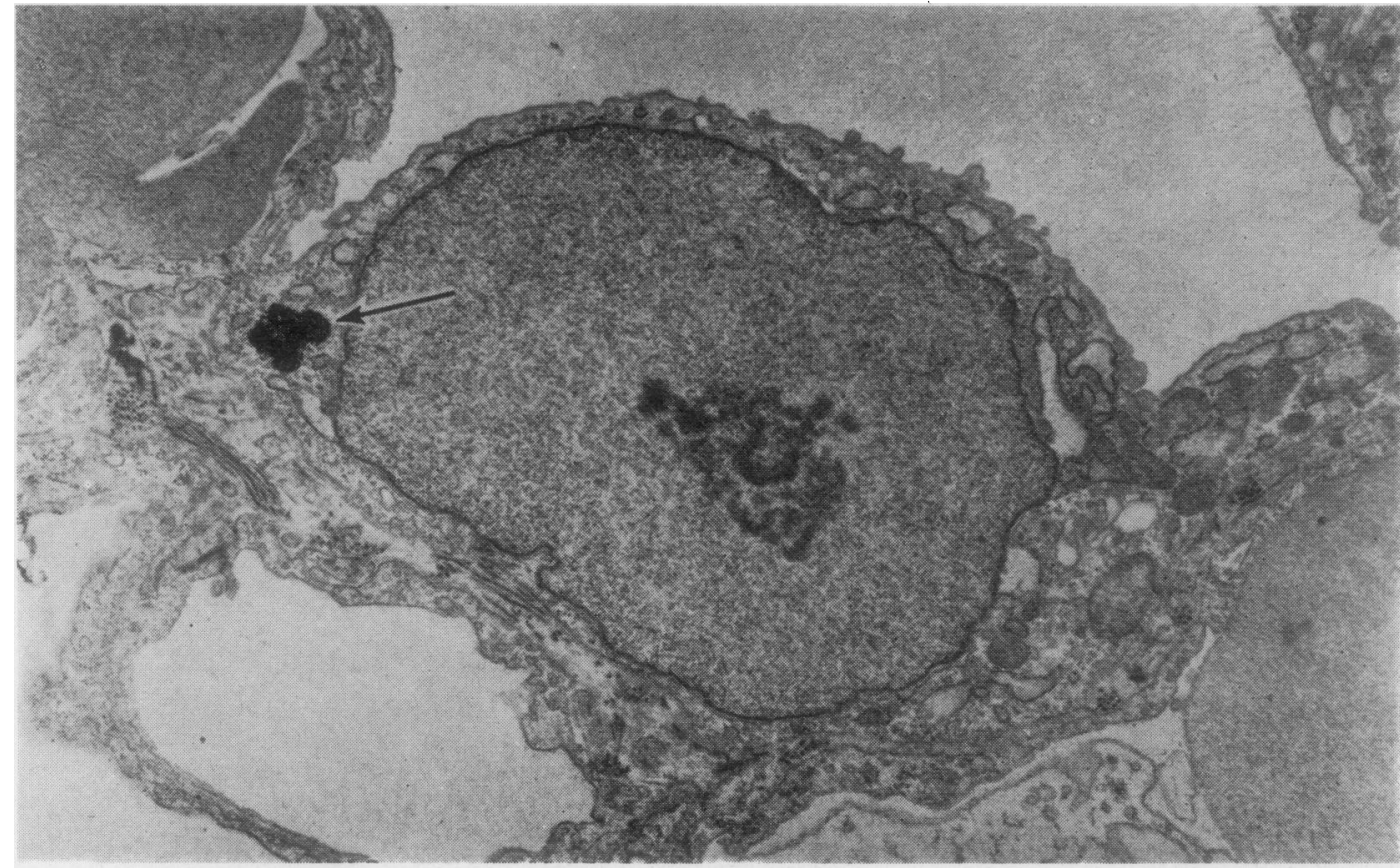

FIG. 2. A type I pneumocyte in which there is a small phagosomal vacuole well filled with thorium (arrow), 48 hours after injection. Lead citrate $\times 9,000$.

the individual lamellae (Fig. 1). Careful attention was required to detect these few particles. After 26 hours thorium disappeared entirely from type II cells.

Type I pneumocytes were also found to contain thorium. From 19 hours occasional thorium-filled vacuoles were observed and, although scanty, were easily detectable (Fig. 2). Compared with those in macrophages these vacuoles were small, whilst compared with the lamellar vacuoles of the type II pneumocytes they were well filled with thorium. The relative amounts of thorium in the macrophages and the two varieties of epithelial cell are well shown in Figure 3. In addition to the well-filled phagosomal vacuoles, type I cells also contained occasional thorium particles within pinocytotic vesicles, including some opening on to the basement membrane. An interstitial macrophage was sometimes found to contain thorium, but, compared with alveolar macrophages, the interstitial cells possessed fewer and smaller phagosomal vacuoles. Carbon was found in no cells other than alveolar macrophages.

\section{DISCUSSION}

Whilst this work demonstrates the entry of foreign material into alveolar macrophages and both types of alveolar epithelial cell, the relative differences $\overrightarrow{\overrightarrow{0}}$ in phagocytic activity between these cell types are 3 immense and do not necessarily support an epi吾 thelial origin for the free macrophages, as suggested by some workers (see discussion by Spencer, 1968). The phagocytic potential of the epithelial cells is low, but of particular interest is $x$ the localization of foreign material in the vacuoles 3 of the type II pneumocytes widely regarded as the site of surfactant secretion. In conjunction witho our earlier demonstration of acid phosphatase and aryl sulphatase in the same location (Corrin and? Clark, 1968 ; Corrin et al., 1969), this could well be taken to support Niden's hypothesis that type II pneumocytes are concerned with the disposalN rather than synthesis of surfactant. If this is correct, however, the phagocytic process must be remarkably selective, for the amount of thoriumw entering the type II cell is exceptionally small des? pite the large amounts available, whereas surface tant is scanty within the alveolar space yet large amounts of phospholipid are present within th? type II pneumocytes. Alternatively, the dispropor- $-\frac{T}{9}$ tionate amounts of thorium and surfactant within the cell might be due to a few particles of thorium $\stackrel{\mathbb{\Omega}}{\Omega}$ entering the vacuoles as these structures open on $\stackrel{\mathbb{Q}}{2}$ to the cell surface to discharge their content of surfactant. That this may be the case is suggestado 


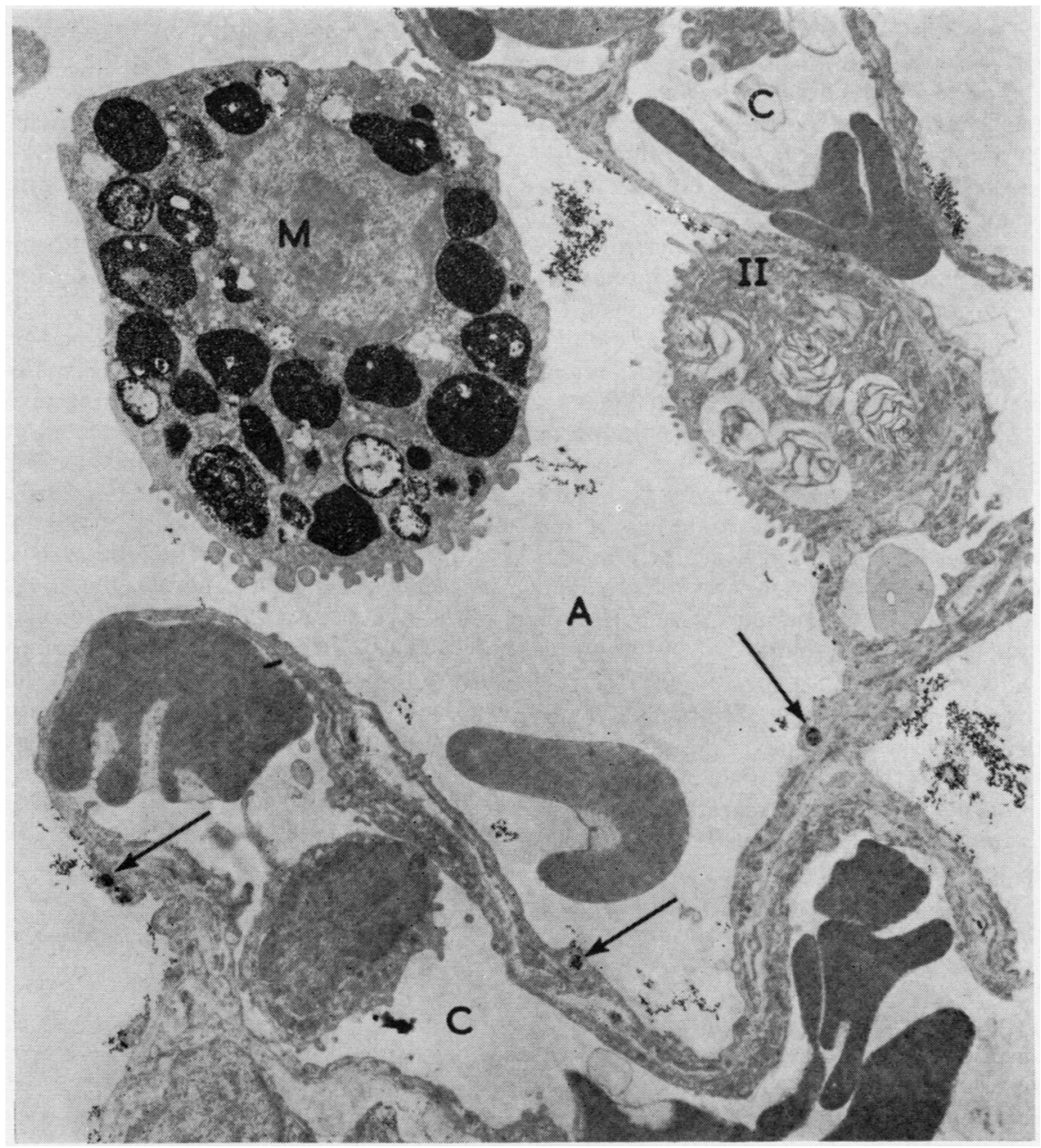

FIG. 3. This area of the lung is representative of the relative phagocytic activity of the various cell types. An alveolar macrophage $(M)$ free in the alveolar air space $(A)$ contains numerous, large, well-filled phagosomal vacuoles. Smaller scanty phagosomes in type I epithelial cells are indicated by arrows, whilst minute amounts of thorium in a type II pneumocyte (II) are barely perceptible at this magnification but are in fact present in the most central of its six lamellar vacuoles. Free thorium is also present in the alveolar space. 26 hours after injection. $C=$ capillary. Unstained $\times 2,300$.

by the disappearance of thorium from the type II pneumocyte after 26 hours. In type I cells, on the other hand, thorium occupied small, scanty, but well-filled vacuoles which persisted over five days. These cells therefore appear to possess limited but genuine phagocytic ability, whereas the minute amount of thorium found in type II pneumocytes possibly represents a purely passive phenomenon.

The presence of lysosomal enzymes in the lamellar vacuoles naturally suggests a phagocytic nature, but such enzymes have also been demonstrated in secretory cells elsewhere, where they are thought to be concerned in the release of the secretory product (Smith and Farquhar, 1966). Lytic enzymes may also contribute to a synthetic process by liberating necessary precursor substances. Aryl sulphatase acts in this way in the developing brain, hydrolysing cerebroside sulphate ester produced in glycosphingolipid metabolism, to make available free cerebroside for incorpora- 
tion into the myelin sheath (Choy and Cravioto, 1968). Similarly, phosphatidic acid phosphatase occupies a key role in lipid metabolism. Triglyceride and phospholipid synthesis both depend upon diglyceride, but this cannot be produced by direct acylation of glycerol. Instead, diglyceride is released by the action of phosphatase on intermediary phosphatidic acid. The presence of two such lysosomal enzymes in the lamellar inclusions of type II pneumocytes is therefore not necessarily incompatible with a secretory function. Whilst both our present findings and previous histochemical results are in agreement with Niden's hypothesis, alternative explanations are therefore available and the importance of the type II pneumocyte in surfactant synthesis is by no means disproved. Indeed recent sequential studies of the type II pneumocyte following pilocarpine stimulation (Goldenberg, Buckingham, and Sommers, 1969) strongly reinforce the popular conception of this cell as being the source of pulmonary surfactant.

Niden's rejection of the type II pneumocyte as an essentially secretory cell appears premature, but his suggestion of the bronchiolar Clara cell as an alternative site of surfactant secretion will undoubtedly stimulate further interest in these relatively neglected cells. Resolution of the problem of the site of surfactant synthesis will ultimately come from ultrastructural autoradiographic studies of pulmonary lipid metabolism. Technical obstacles have so far prevented such an electron microscopic study whilst by conventional microscopic autoradiography contradictory results have been obtained, some pointing to the type II pneumocyte (Buckingham, Heinemann, Sommers, and McNary, 1966; Faulkner, 1969) and others to the Clara cell (Niden, 1967). This suggests that these two cells may share the function of surfactant secretion. The Clara cell is rich in lipidic inclusions (Niden, 1967 ; Corrin and Vijeyaratnam, 1969), which would fit better with surfactant secretion than the role of mucus production generally ascribed to these cells (Hayek, 1962). Azzopardi and Thurlbeck (1969) found no evidence of mucus secretion but demonstrated phospholipids and a high activity of oxidative enzymes in the Clara cell. There is therefore strong evidence that the Clara cell may be an alternative or additional site of surfactant sacretion.

The squamous pneumocytes possess limited phagocytic activity and the process of ingestion by these cells appears to be similar to that described in the pericardium, where the particles accumulate in dense bodies, and also appear in pinocyto- tic vesicles (Kluge and Hovig, 1969). Pinocytosis represents fluid transport, but the direction cannot: often be determined. Here, however, thorium par ticles being extruded to the basement membrane indicate that some of the pinocytotic vesicles are crossing from alveolus to interstitium. Transports across squamous pneumocytes by this means is the probable route taken by the thorium observedwithin oscasional interstitial macrophages. This $\vec{\omega}$ however, can only be regarded as a minor route of disposal. The more numerous and heavily ladenk alveolar macrophages form the major clearances mechanism to the exterior and the regional lymphnodes. These cells were not detected crossing into the alveolar walls, but their incorporation into the interstitium in Macklin's dust sumps at the apex of the lung lobules (Policard, Collet, and Preger $\overrightarrow{\vec{c}}$ main, 1957) would not be observed in these ex@ periments. Transport across the alveolar epithe lium in pinocytotic vesicles or phagosoma菜 vacuoles is therefore a relatively minor means of disposal even for colloidal particles, and a similas route is improbable in the case of dust particles in the respirable range of 1 to $5 \mu$ Stokes diametero

I am indebted to Mr. A. E. Clark, Mrs. Margareb Leppard, Miss Valerie Hark. and Miss Marie Simnet: for their excellent technical assistance.

\section{REFERENCES}

Azzopardi, A., and Thurlbeck, W. M. (1969). The histochemistro of the nonciliated bronchiolar epithelial cell. Amer. Rev. res/ Dis., 99, 516.

Bensch, K., Schaefer, K., and Avery, M. E. (1964). Granular pneư mocytes: electron microscopic evidence of their exocrinic. function. Science, 145, 1318.

Buckingham, S., and Avery, M. E. (1962). Time of appearance of lung surfactant in the foetal mouse. Nature (Lond.), 193, 688 - Heinemann, H. O., Sommers, S. C., and McNary, W. F. (1966) Phospholipid synthesis in the large pulmonary alveolar cel. Amer. J. Path., 48, 1027.

Choy, A. E., and Cravioto, H. (1968). A study of aryl sulfatas and acid phosphatase in the developing nervous system of the rat. J. Histochem. Cytochem., 16, 582.

Corrin, B., and Clark, A. E. (1968). Lysomal aryl sulphatase pulmonary alveolar cells. Histochemie, 15, 95 . - and Spencer, H. (1969). Ultrastructural localization of acido phosphatase in the rat lung. J. Anat. (Lond.), 104, 65.

- and Vijeyaratnam, G. S. (1969). Unpublished observations.

Faulkner, C. S. II. (1969). The role of the granular pneumonocyter in surfactant metabolism. An autoradiographic study. Arck Path., 87, 521.

Goldenberg, V. E., Buckingham, S., and Sommers, S. C. (196\% Pilocarpine stimulation of granular pneumocyte secretiog Lab. Invest., 20, 147.

Hayek, H. (1962). Cellular structure and mucous activity in the bronchial tree and alveoli. In Ciba Foundation Symposium om Pulmonary Structure and Function. p. 99, Ed. de Reuck, A. V. SO and O'Connor, $M$. Churchill, London.

Karrer, H. E. (1958). The ultrastructure of mouse lung: the alveol macrophage. J. biophys. biochem. Cytol., 4, 693.

(1960). Electron microscopic study of the phagocytosis process in lung. Ibid., 7, 357. 
King, E. J., Harrison, C. V., Mohanty, G. P., and Yoganathan, M. (1958). The effect of aluminium and of aluminium containing
5 per cent of quartz in the lungs of rats. J. Path. Bact., 75, 429.

Klaus, M., Reiss, O. K., Tooley, W. H., Piel, C., and Clements, J. A. (1962). Alveolar epithelial cell mitochondria as source of the surface-active lung lining. Science, 137, 750.

Kluge, T., and Hovig, T. (1969). Ultrastructural localization of thorotrast in the reticuloendothelial system. Amer. J. Path., 54, 355.

Ladman, A. J., and Finley, T. N. (1966). Electron microscopic observations of pulmonary surfactant and the cells which produce it. Anat. Rec., 154, 372.

Niden, A. H. (1967). Bronchiolar and large alveolar cell in pulmonary phospholipid metabolism. Science, 158, 1323.
Policard, A., Collet, A., and Pregermain, S. (1957). Etude au microscope électronique du granulome pulmonaire silicotique expérimental. Presse méd., 65, 121.

Smith, R. E., and Farquhar, M. G. (1966). Lysosome function in the regulation of the secretory process in cells of the anterior pituitary gland. J. Cell Biol., 31, 319.

Sorokin, S. P. (1966). A morphologic and cytochemical study of the great alveolar cell. J. Histochem. Cytochem., 14, 884.

Spencer, H. (1968). Pathology of the Lung. 2nd ed., p. 39. Pergamon Press, Oxford.

Suzuki, Y., Churg, J., and Smith, W. (1968). Phagocytosis of asbestos fibers by epithelial cells. Lab. Invest., 18, 335 . 